\title{
Learner Presence Matters: A Learner-Centered Exploration into the Community of Inquiry Framework
}

\author{
Catherine A. Honig and Diane Salmon \\ National Louis University
}

\begin{abstract}
The present study explored the Community of Inquiry (CoI) framework, a theoretical structure identifying processes leading to effective online learning, within one particular learning context. Drawing from research supporting the significance of three presences - teaching, social, and cognitive - this study augments a line of research on a potential fourth presence, learner presence, by employing a mixed-method approach to investigate learner perceptions, thoughts, and actions in MBA online/blended courses. Stimulated recall interviews with individual learners regarding their course experience highlighted three qualities of the learners' presence in their courses: intentions, metacognition, and peer monitoring. They also pointed to ways in which certain facets of the three CoI presences supported these qualities. The findings prompted questions for further CoI research investigating learner presence and suggested implications for learner-centered course design and online instruction.
\end{abstract}

Keywords: community of inquiry, learner presence, online MBA

Honig, C.A. \& Salmon, D. (2021). Learner presence matters: A learner-centered exploration into the community of inquiry framework. Online Learning, 25(2), 95-119. https://doi.org/10.24059/olj.v25i2.2237

\section{Learner Presence Matters:}

\section{A Learner-Centered Exploration of the Community of Inquiry Framework}

Recent research reports describing the status of online education in the U.S. confirm continued, steady growth in the distance education sector (e.g., Allen \& Seaman, 2016; Allen \& Seaman, 2017; Seaman, Allen, \& Seaman, 2018). Approximately $32 \%$ of college students-more than 6 million - are participating in online education (Seaman et al., 2018). The ubiquity of online learning and its increasing strategic importance with respect to higher education has led to substantial interest in evaluating its impact and effectiveness. Research findings compiled on the No Significant Difference website suggest that different modes of course delivery are largely equivalent (https://detaresearch.org/research-support/no-significant-difference/). However, a 
review of meta-analytic studies comparing online and face-to-face delivery revealed mixed results where student outcomes are concerned (Nguyen, 2015). Moreover, recent large-sample research has demonstrated lower grades and lower persistence for students taking online (vs. face-to-face) courses (e.g., Bettinger \& Loeb, 2017). Taken together, these findings raise important questions about the various factors and conditions that reinforce learning (and other positive outcomes) in online courses, and they point to the value of investigating them.

The field of online learning is associated with a small but nonetheless compelling constellation of theoretical frameworks that enhance our understanding of the processes leading to online learning effectiveness (e.g., Piccanio, 2017). Among the most studied and cited is the Community of Inquiry (CoI) framework (Garrison, Anderson, \& Archer, 2000). This paper reviews the research on the $\mathrm{CoI}$ framework, its three core presences, and examine lines of inquiry suggesting the need for a fourth presence. Learner presence has emerged as a potential addition to the original CoI framework (e.g., Anderson, 2018; Shea \& Bidjerano, 2010, 2012). The present study investigates this potential by eliciting learners' perceptions, thoughts, and actions on their experience in MBA online and blended courses. Findings from both the CoI Survey and in-depth interviews illustrate how learners experience a community of inquiry and provide insights into the nature of $\mathrm{CoI}$ in one unique learning context.

\section{Review of Related Literature}

\section{The Community of Inquiry (CoI) Framework}

Originally proposed 20 years ago, the CoI framework is grounded in a social constructivist tradition that underlines the role of collaborative inquiry in knowledge construction (e.g., Anderson, 2018; Garrison, et.al., 2000). The CoI has been researched extensively in numerous learning environments. (See the CoI website at https://coi.athabascau.ca/ for a review of the CoI framework and for a repository of published CoI research.)

\section{Figure 1}

Community of Inquiry Framework (Garrison et al., 2000).

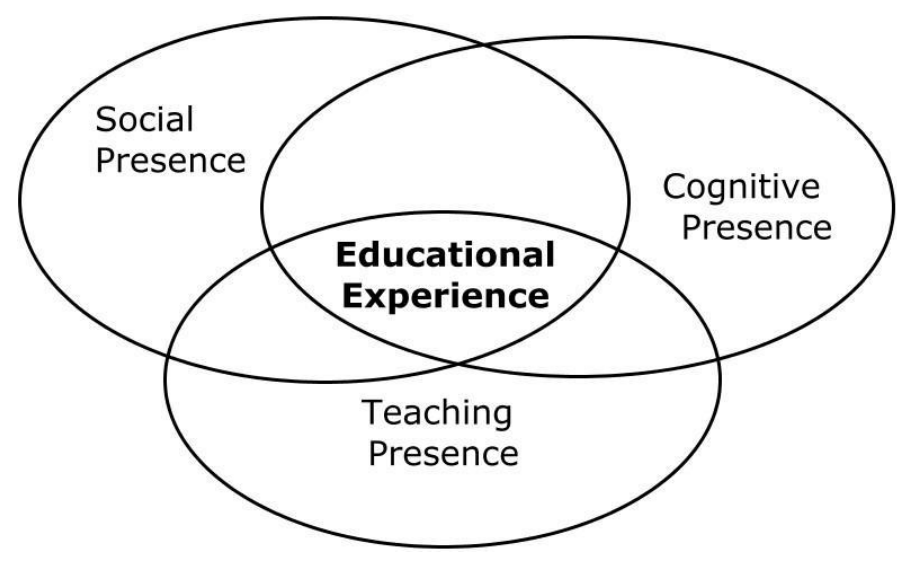


The CoI framework comprises three dimensions as depicted in Figure 1-teaching presence, social presence, and cognitive presence. The underlying thesis is that intentional development of the three presences yields a robust learning experience, and research confirms a relationship between the CoI presences and student outcomes such as satisfaction with online course discussions (Swan \& Shih, 2005), deep vs. surface learning approaches (Garrison \& Cleveland-Innes, 2005), perception of learning and delivery medium satisfaction (Arbaugh, 2008), and persistence (e.g., Boston et al., 2009).

Table 1 below presents the definitions of the three presences as originally conceived by Garrison et al. (2000) and then further developed over time. Most recently, these definitions have been operationalized via the validation of a 34-item Community of Inquiry Survey (e.g., Swan et al., 2008), an instrument that has been developed to assess the three presences. Teaching presence references the design and organization of the course, instructor facilitation (such as guiding behaviors), and direct instruction behaviors such as feedback. Social presence is associated with course-related dynamics that relate to affective expression, open communication, and group cohesion. Cognitive presence incorporates a four-phase process of practical inquiry (e.g., Garrison, 2009) and encompasses triggering events (such as a motivating class activity), exploration, integration, and resolution. Importantly, the three presences are interrelated. Together, they create an educational community that is defined by productive collaboration and inquiry.

\section{Table 1}

Teaching Presence, Social Presence, and Cognitive Presence

\begin{tabular}{ll}
\hline $\begin{array}{l}\text { Teaching } \\
\text { Presence }\end{array}$ & $\begin{array}{l}\text { "The design, facilitation, and direction of cognitive and social processes } \\
\text { for the purpose of realizing personally meaningful and educationally } \\
\text { worthwhile learning outcomes" (Anderson, Rourke, Garrison, \& Archer, } \\
\text { 2001, Describing Teaching Presence section, para.1). }\end{array}$ \\
$\begin{array}{l}\text { Social } \\
\text { Presence }\end{array}$ & $\begin{array}{l}\text { "The ability of participants to identify with the community (e.g., course of } \\
\text { study), communicate purposefully in a trusting environment, and develop } \\
\text { interpersonal relationships by way of projecting their individual } \\
\text { personalities" (Garrison, 2009, p. 352). }\end{array}$ \\
$\begin{array}{l}\text { Cognitive } \\
\text { Presence }\end{array}$ & $\begin{array}{l}\text { "Extent to which learners are able to construct and confirm meaning } \\
\text { through sustained reflection and discourse in a critical community of } \\
\text { inquiry" (Garrison, Anderson, \& Archer, 2001, p. 11). }\end{array}$ \\
\hline
\end{tabular}

Early research on the CoI began with an examination of the individual presences via content analysis of online course discussions and then subsequently moved toward large-sample validation studies. Both forms of research have played pivotal roles in exploring and defining the three presences.

The development of coding categories and templates for content analysis helped paint a behavior-based picture of how the three presences manifest in text-based class discussion and provided a foundation for assessing CoI patterns in online courses. These studies proved invaluable in making explicit the definitions of the three presences, demonstrating their occurrence in online courses, and surfacing important pedagogical insights (e.g., Anderson et al., 2001; Garrison et al., 2001; Garrison \& Cleveland-Innes, 2005). In a review of the first decade of CoI research, Garrison, 
Anderson, and Archer (2010) acknowledged the methodological challenges inherent in transcript analysis but also pointed to numerous important findings and perspectives that emerged from early work on the CoI. These included the emerging prominence of teaching presence, the evolving definition of social presence as multidimensional and "temporal" (i.e., progressing over time), and the understanding that course design and leadership (i.e., teaching presence) likely play a key role in helping students move to higher-level phases of practical inquiry (cognitive presence).

While coding for CoI presences went a long way toward launching an exploration of the framework and describing the individual presences, calls for a transition to quantitative approaches emerged as it became clear that survey development and large-scale cross-institutional research would beneficially strengthen and expand the empirical investigation of the framework (e.g., Garrison \& Arbaugh, 2007). Answering this call and building on preceding CoI research, a stream of factor analytic research studies validated a three-factor $\mathrm{CoI}$ structure, illuminated the interrelationships among the three presences, and illustrated the impact of the CoI presences on student perceptions of learning and satisfaction. Arbaugh (2007) originally found a four-factor solution in which course design and organization emerged as a fourth factor, but subsequent research congealed around the three originally proposed dimensions with course design and organization falling within teaching presence (e.g., Arbaugh, 2008; Arbaugh et al., 2008; Diaz, Swan, Ice, \& Kupczynski, 2010; Garrison, Cleveland-Innes, \& Fung, 2010; Swan et al., 2008). Notably, Swan et al. (2008) collaboratively developed a 34-item CoI survey instrument and tested its efficacy on a multi-institutional, multi-disciplinary sample of students taking CoI-designed courses. The results validated the three-dimension CoI framework and launched the survey for use in both research and teaching-related (e.g., course design) settings.

Factor analytic studies produced numerous significant findings, many of which appeared to support the important role of teaching presence as described in the original conception of the CoI framework (Garrison et al., 2000). Garrison, Cleveland-Innes, and Fung (2010) demonstrated teaching presence as a direct driver of cognitive presence with social presence operating as a mediator between the two. Diaz et al. (2010) found that while students rated all three presences as important, they rated teaching presence as more important vs. cognitive or social presenceperhaps signaling their understanding of its primary role in influencing class interaction and, ultimately, learning. Arbaugh (2008) found that teaching presence and cognitive presence were strong predictors of students' ratings of perceived learning while social presence was a stronger predictor of delivery medium satisfaction, lending credence to the view that teaching presence and cognitive presence are primary with respect to (perceived) learning while social presence plays a less direct (albeit important) role.

In all, content analysis of online course discussions supported the existence of the three presences and illustrated their manifestation in online discourse. Large-sample factor analytic investigations have confirmed a tri-dimensional framework, guided the development of the CoI survey, and explored how the three presences are related to each other and to student outcomes.

\section{Emergence of Learner Presence}

The contribution of $\mathrm{CoI}$ research to online learning theory is notable for its explication of the dimensions of an online community. However, an expanding line of CoI-related research has revealed learner thoughts and actions not captured by the three CoI presences and that might be described as self-directed. These have ranged from student discourse related to working on group assignments (e.g., Shea, Hayes, \& Vickers, 2010) to surfing for and sharing additional course 
references (Lam, 2015) to self-reported coordination of learning activities with class group members (e.g., Pool, Reitsma, \& van den Berg, 2017). To address these findings, some researchers have suggested the expansion of the $\mathrm{CoI}$ framework to incorporate a fourth presence, learner presence (e.g., Lam, 2015; Shea \& Bidjerano, 2010, 2012). A compelling case for the addition of learner presence is offered by Anderson (2018), one of the original CoI researchers: "It is no longer enough for teachers to ask what types of presence(s) do I need to develop in my teaching, but rather how do I match my teaching model and behavior with the learning capacities of the learners" (Need for Additional Presences to Define a Community of Inquiry section, para. 2).

Research evidence in support of learner presence is noteworthy. In a sample of 3165 undergraduate students, Shea and Bidjerano (2010) found that learners' perceptions of teaching presence and social presence were significantly correlated with their ratings of self-efficacy (a potential component of learner presence). The authors offered a revised $\mathrm{CoI}$ model in which "learning presence" mediates the relationships among teaching presence, social presence, and cognitive presence. Moreover, the authors compared blended and online courses and found that teaching presence and student self-efficacy were more strongly related in blended (vs. fully online) courses. These results suggested that expanded teaching presence might be needed to support selfefficacy in online students. They built upon these findings in a subsequent study of 2,010 college students (Shea \& Bidjerano, 2012) and demonstrated that when teaching or social presence is low, learner self-regulation (the authors' definition of learning presence) acts as a compensating factor in the development of cognitive presence.

Continuing to focus closely on self-regulated learning (SRL) and calling on theory and research in SRL (e.g., Zimmerman, 2008), Shea et al. (2012) coded learner discourse in two online courses and found that learners exhibited self-regulation and co-regulation as defined by forethought/planning, monitoring, and strategy use. These extra-CoI behaviors increased when learners participated in a collaborative course activity. Moreover, learning presence in this study was positively correlated with grades, reinforcing the value of examining regulatory learning as (an aspect of) learning presence. A follow-on study that employed learner-facilitated online course discussions and social network analysis further found that learners with higher learning presence (defined in this study as self- and co-regulation) achieved network positions that identified them as "valuable partners for interaction and the knowledge building meant to result from it" (Shea et al., 2013, p. 445). In further exploration of learning presence as a regulatory learning construct, Hayes, Uzuner Smith, and Shea (2015) coded online discourse among student teams who were working on assigned group projects. Transcript analysis illustrated learning presence as manifesting at three levels: self-regulation, co-regulation, and shared regulation. In an apparent nod to teaching presence, the authors shared instructional strategies that faculty can use to support learner presence.

Qualitative research in blended learning environments offered perspectives on the nature of learner presence within different disciplinary contexts. Lam (2015) found that managerial accounting students exhibited various self-directed learning behaviors-such as searching for unassigned external resources or collaborating via social media. Her focus was on the actions students initiated on their own to accomplish course activities. Rather than referring to these behaviors as self-regulation or learner presence, she termed them autonomy presence and concluded that this fourth presence advanced student learning. Pool, Reitsma, and van den Berg (2017) also employed a qualitative research approach to examine learner presence in a CoIdesigned blended course for teacher education students. Analysis of focus group interviews and 
Facebook threads led the authors to conclude that students struggled with self-regulation — such as managing time and coordinating tasks - in the online side of the course. The authors concluded that the lack of self-regulation skills heightened the importance of teaching presence in online learning.

Narrowing the emphasis to metacognition, Garrison and Akyol (2013) developed and validated a metacognition questionnaire that asked students to rate their metacognitive skills as individual learners (e.g., "I am aware of my level of learning") and also as learners who are members of a larger class community (e.g., "I reflect upon the comments of others"). The results of their factor analytic validation study confirmed a two-factor metacognition construct having both individual and "mutual support" components (i.e., self-regulation and co-regulation). The authors raised the specter of follow-up research having both theoretical and practical implications, including an exploration of the relationships among self-regulation, co-regulation, and the CoI presences as well as research aimed at identifying practices for supporting co-regulation in courses. Of particular interest, however, is that the authors do not refer to the shared metacognition construct as learning presence (or learner presence). On the contrary, original CoI researcher Garrison (2017) has offered a perspective that the shared metacognition construct precludes the need for a fourth presence by effectively capturing the collaborative nature of thinking and learning that is inherent in the CoI model. Moreover, he has defined shared metacognition as already located within the CoI model at the "intersection of cognitive and teaching presence" (para. 4).

\section{Examining Learner Presence in Context: One Pathway Forward}

The question of whether learner presence ought to be a fourth CoI presence or whether it is sufficient to say that it lies at the intersection of teaching presence and cognitive presence is complex. As described above, Garrison (2017) argues convincingly that a fourth presence is redundant. Still, the research suggests that the learner presence construct has the potential to offer an enhanced understanding of CoI. The nature of the construct points to important relationships with the CoI presences and suggests potential for advancing individual and shared learning in online learning communities. Regardless of whether it is a fourth presence or whether it is an emergent construct within and between the dynamics of the CoI, learner presence bears further investigation. Researchers have defined, named, and investigated it in different ways leading to a variety of definitions. Given the diversity of both learners and learning contexts, this variation makes sense. Hence, the present study explores learner presence as an emergent construct involving thoughts and actions initiated by students in response to a particular learning environment. This pathway forward invites a closer examination of learner presence in one specific learning context.

Following this line of reasoning, this study examined the nature of the learner presence (and CoI) in a very specific learning environment, an accelerated MBA Online Program (6-week courses) whose students are working professionals. Generating more empirical research within particular educational contexts can deepen our understanding of the CoI in relation to particular learners and learning goals. Although several studies specifically have sampled business students (e.g., Arbaugh, 2008; Lam, 2015) and others incorporated large samples from a broad array of disciplines (e.g., Swan et al., 2008), research such as Akyol, Vaughn, and Garrison's (2011) exploration of course duration or Lambert and Fisher's (2013) investigation of CoI patterns in an individual educational technology course demonstrates how research on specific contexts augments the CoI knowledge base. 
The study further investigated the nature of learner presence via a qualitative research approach that entailed systematic one-on-one stimulated recall interviews tapping into individual learners' unique experience within a particular course environment. While large-sample factor analytic research has played an inarguably important role in establishing self-efficacy and selfregulation as central to learner presence (e.g., Shea \& Bidjerano, 2010, 2012) a qualitative investigation in the MBA learning context that examines how skilled learners describe their own thoughts and actions in relation to factors of teaching presence, social presence, and cognitive presence provided further elaboration of the learner presence construct.

An accelerated online MBA Program with a nontraditional student population is an interesting and worthwhile context in which to examine learner presence. Business education is changing rapidly, and nontraditional delivery approaches (in general) and online learning (in particular) are expected to become increasingly prominent (e.g., Belsky, 2019). Learning research in this context capitalizes on an opportunity to examine the learner presence construct and refine our understanding of the dynamics between the CoI presences, particular learners, and particular course environments.

\section{Research Questions}

Research findings on the CoI speak to the usefulness of the CoI framework in researching, explaining, and developing the processes that contribute to the development of effective collaborative learning environments. In addition, they point to directions for continued research regarding the nature of learner presence in particular learning contexts. This research addressed this direction through the following research questions.

1. To what degree do students in an accelerated MBA program for working professionals experience their courses as a community of inquiry?

2. How can we characterize the nature of learner presence in this learning environment? What features of the CoI model seem to facilitate this learner presence?

\section{Methods}

\section{Overview of Research Design and Context}

This research project was supported by a university seed grant that required completion of all aspects of the research process (including data collection and analysis) within the space of one year. The project was approved by the university's Institutional Review Board (IRB).

Examination of the research questions was accomplished through a mixed method research design. All MBA students taking classes during the Fall and Winter terms were invited to complete the CoI survey with regard to the particular MBA course they had taken. Those students who agreed to be interviewed were further contacted to engage in a semi-structured one-on-one interview regarding their approach to learning in the course. The MBA program is housed within a small Midwestern nonprofit private university and enrolls between 130 and 150 students annually. The program is remarkable for a number of features. First, courses in this MBA Program are accelerated (six weeks in length) and are delivered in fully online or blended (50\% online and $50 \%$ face-to-face) formats. Second, all courses adhere to (a) defined course design and delivery standards, (b) a program-wide leadership theme, and (c) key course learning outcomes through fully populated online course templates. Third, weekly participation in online course discussions 
is required of both students and faculty in all online and blended courses. Overall, the courses are brief yet intense with high expectations for continuous discourse.

\section{Participants}

A sample of 21 MBA students completed the CoI survey, approximately $16 \%$ of students active in the program. All were taking online and blended courses during the 2018-19 academic year. All participants were working professionals who hailed from a wide variety of businesses and industries. Approximately one-half were new to online learning when they entered the MBA Program. Of the 21 completing the survey, six students (four women and two men) agreed to participate in an individual interview regarding their experience of the particular MBA course on which they completed the survey. The student interviewees were representative of the university's larger MBA student population and of MBA students in general: a dual-gender, ethnically diverse group of men and women at early $(n=4)$, mid $(n=1)$, and later career stages $(n=1)$. Five were employed across a broad range of industry settings, and one was a self-employed entrepreneur. The preponderance of women in the interview sample directly reflects the percent of women in the MBA Program which served as the focus of this study.

\section{Measures}

CoI Survey. Measurement of the three CoI presences was accomplished via electronic administration of the validated 34-item CoI Survey. Several additional survey items were developed and added to address participants' prior experience as online learners and to capture information related to the delivery method and subject matter of the courses that students were taking at the time the survey was administered. (See the Community of Inquiry website at http://www.thecommunityofinquiry.org/ for a copy of the CoI Survey.)

Interview Protocol. A 30 to 45-minute semi-structured interview protocol was designed to follow up on survey findings and to systematically explore how a learner's presence manifested within a specific MBA course. All interviews were held on the Zoom Video Conference platform and recorded for later analysis. The interview protocol invited each participating student to "think aloud" as she or he viewed an online course in D2L through the screen sharing feature in Zoom. Specific questions guided each student to focus on key features of the course and to recall her or his actions and thoughts with regard to components. One researcher scrolled through the course so the student could view each component as the other probed the student's thoughts and actions. The focal course components included the (a) course organization in general (i.e., table of contents), (b) most compelling course module,

(c) discussion forums in general, (d) most compelling course discussion, (e) course assignments in general, and (f) most compelling course assignment. (See Appendix for a copy of the interview protocol.)

\section{Procedure}

All MBA students taking classes during the Fall and Winter terms were notified electronically about the opportunity to participate in the research study. Participants came from 11 unique MBA courses. Seven of these courses were online, two were offered in both online and blended formats, and two were blended only. The email invitation was sent during both terms (Fall and Winter) and included the following explanation of the research.

Our research explores the Community of Inquiry (CoI) framework, which underlines the role of collaborative inquiry in developing an effective learning 
experience. Through this research we hope to gain deeper insight into the quality of the learning community that our MBA courses foster and how we might continue to improve the learning experience.

Data collection involved both surveys and interviews and took place over two academic quarters. MBA students who volunteered to take the CoI Survey were asked to "think about the MBA course that you are currently taking or have most recently completed." On completing the survey, students were asked if they would be willing to participate in an individual in-depth interview. The survey sample reached 21 with some MBA students participating more than once across courses, thus resulting in 32 completed surveys. Six students volunteered to participate in the interviews. One MBA student participated in two interviews (for two different courses), thus resulting in seven completed in-depth interviews.

\section{Data Analysis}

Research question 1 (the degree to which students perceived the MBA as a CoI) was addressed through an analysis of the CoI survey data from the 21 participants. Descriptive statistics (means and standard deviations) and frequency data were calculated to represent the CoI ratings. Research question 2 (the nature of learner presence in the MBA) was addressed through the interview data. The interview recordings were independently reviewed by each researcher and partially transcribed. Specific learner thoughts and actions were identified in relation to the key course components. Common thoughts and actions were then identified across interviewees and represented in a concept map format. Interview recordings were again reviewed and the concept map pruned for clarity and parsimony.

\section{Results}

\section{RQ 1: Do the MBA Students Experience their Courses as a Community of Inquiry (CoI)?}

Grand means of the three presences were calculated to address RQ 1. Mean ratings across the three presences exceeded 4.0 (on a 5-point scale) and confirmed overall agreement that teaching presence $(M=4.01, S D=.21)$, cognitive presence $(M=4.08, S D=.13)$, and social presence $(M=4.24, S D=.30)$ were evident in the MBA course sections that students rated.

Examination of the survey results by each of the three CoI presences revealed a more nuanced picture of students' CoI perceptions. Table 2 presents the results for teaching presence. where ratings above 4.0 suggested that this presence was most strongly felt via course organization-i.e., communication of important course topics $(M=4.13, S D=1.10)$, course goals $(M=4.28, S D=.85)$, clear instructions $(M=4.31, S D=.86)$, and important due dates $(M=4.34$, $S D=.94)$. Providing timely feedback $(M=4.16, S D=1.19)$ - a component of direct instructionalso was more highly rated. However, various ratings associated with facilitation behaviors received ratings below 4.0 (indicating less agreement about the degree to which these behaviors were present). One exception was the rating for encouraging course participants to explore new concepts $(M=4.00, S D=1.16)$. 
Table 2

Teaching Presence (CoI): Means, Standard Deviations, and Percentages

\begin{tabular}{|c|c|c|c|c|c|}
\hline & Mean & SD & $\begin{array}{c}\% \\
\text { Agree }\end{array}$ & $\begin{array}{c}\% \\
\text { Neutral }\end{array}$ & $\begin{array}{c}\% \\
\text { Disagree }\end{array}$ \\
\hline TEACHING PRESENCE & 4.01 & .21 & & & \\
\hline $\begin{array}{l}\text { The instructor clearly communicated } \\
\text { important course topics. }\end{array}$ & 4.13 & 1.10 & $81.3 \%$ & $6.3 \%$ & $12.5 \%$ \\
\hline $\begin{array}{l}\text { The instructor clearly communicated } \\
\text { important course goals. }\end{array}$ & 4.28 & .85 & $81.3 \%$ & $15.6 \%$ & $3.1 \%$ \\
\hline $\begin{array}{l}\text { The instructor provided clear } \\
\text { instructions on how to participate in } \\
\text { course learning activities. }\end{array}$ & 4.31 & .86 & $87.5 \%$ & $6.3 \%$ & $6.3 \%$ \\
\hline $\begin{array}{l}\text { The instructor clearly communicated } \\
\text { important due dates/time frames for } \\
\text { learning activities. }\end{array}$ & 4.34 & .94 & $87.6 \%$ & $3.1 \%$ & $9.4 \%$ \\
\hline $\begin{array}{l}\text { The instructor was helpful in identifying } \\
\text { areas of agreement and disagreement on } \\
\text { course topics that helped me to learn. }\end{array}$ & 3.81 & 1.23 & 56.3 & $28.1 \%$ & $15.6 \%$ \\
\hline $\begin{array}{l}\text { The instructor was helpful in guiding the } \\
\text { towards understanding course topics in a } \\
\text { way that helped me clarify my thinking. }\end{array}$ & 3.94 & 1.24 & $75.0 \%$ & $12.5 \%$ & $12.5 \%$ \\
\hline $\begin{array}{l}\text { The instructor helped to keep course } \\
\text { participants engaged and participating } \\
\text { in productive dialogue. }\end{array}$ & 3.88 & 1.21 & $71.9 \%$ & $12.5 \%$ & $15.6 \%$ \\
\hline $\begin{array}{l}\text { The instructor helped keep the course } \\
\text { participants on task in a way that helped } \\
\text { me to learn. }\end{array}$ & 3.75 & 1.32 & $65.6 \%$ & $15.6 \%$ & $18.8 \%$ \\
\hline $\begin{array}{l}\text { The instructor encouraged course } \\
\text { participants to explore new concepts in } \\
\text { this course. }\end{array}$ & 4.00 & 1.16 & $71.9 \%$ & $18.8 \%$ & $9.4 \%$ \\
\hline $\begin{array}{l}\text { Instructor actions reinforced the } \\
\text { development of a sense of community } \\
\text { among course participants. }\end{array}$ & 3.84 & 1.17 & $62.5 \%$ & $28.1 \%$ & $9.4 \%$ \\
\hline $\begin{array}{l}\text { The instructor helped to focus discussion } \\
\text { relevant issues in a way that helped me } \\
\text { to learn. }\end{array}$ & 3.81 & 1.26 & $71.9 \%$ & $12.5 \%$ & $15.6 \%$ \\
\hline $\begin{array}{l}\text { The instructor provided feedback that } \\
\text { helped me understand my strengths and } \\
\text { weaknesses relative to the course's goals } \\
\text { and objectives. }\end{array}$ & 3.84 & 1.39 & $71.9 \%$ & $9.4 \%$ & $18.8 \%$ \\
\hline $\begin{array}{l}\text { The instructor provided feedback in a } \\
\text { timely fashion. }\end{array}$ & 4.16 & 1.19 & $81.2 \%$ & $6.3 \%$ & $12.5 \%$ \\
\hline
\end{tabular}

Note. $\mathrm{n}=32 ; 5=$ strongly agree 
Table 3 presents students' ratings of cognitive presence where the highest rated scale underlined exploration. Students agreed that they used a "variety of information sources to explore problems posed in this course" $(M=4.31, S D=.82)$. Likewise, students agreed that "brainstorming and finding relevant information helped [them] resolve content-related questions" $(M=4.19, S D$ $=.93$ ) and that "online discussions were valuable in helping [them] appreciate different perspectives" $(M=4.09, S D=1.09)$.

Other features of cognitive presence-triggers, integration, resolution-presented a somewhat "mixed bag" of results. For example, students agreed that the "problems posed increased [their] interest in course issues" $(M=4.19, S D=.90)$, that learning activities helped them "construct explanations/solutions" $(M=4.16, S D=.99)$, and that they could "apply the knowledge created in this course to my work or other non-class related activities" $(M=4.13, S D=1.19)$. Nonetheless, three parallel scales received ratings below 4.0: (a) "course activities piqued my curiosity" ( $M=3.88, S D=1.26)$; (b) "reflection on course content and discussions helped me understand fundamental concepts in this class" $(M=3.91, S D=1.17)$; and (c) "I can describe ways to test and apply the knowledge created in this course" $(M=3.94, S D=1.13)$.

\section{Table 3}

Cognitive Presence (CoI): Means, Standard Deviations, and Percentages

\begin{tabular}{|c|c|c|c|c|c|}
\hline & Mean & SD & $\begin{array}{c}\% \\
\text { Agree }\end{array}$ & $\begin{array}{c}\% \\
\text { Neutral }\end{array}$ & $\begin{array}{c}\% \\
\text { Disagree }\end{array}$ \\
\hline COGNITIVE PRESENCE & 4.08 & .13 & & & \\
\hline $\begin{array}{l}\text { Problems posed increased my } \\
\text { interest in course issues. }\end{array}$ & 4.19 & .90 & $81.3 \%$ & $12.5 \%$ & $6.3 \%$ \\
\hline $\begin{array}{l}\text { Course activities piqued my } \\
\text { curiosity. }\end{array}$ & 3.88 & 1.26 & $75 \%$ & $9.4 \%$ & $15.6 \%$ \\
\hline $\begin{array}{l}\text { I felt motivated to explore } \\
\text { content related questions. }\end{array}$ & 4.06 & 1.11 & $78.2 \%$ & $9.4 \%$ & $12.5 \%$ \\
\hline $\begin{array}{l}\text { I utilized a variety of information } \\
\text { sources to explore problems posed } \\
\text { in this course. }\end{array}$ & 4.31 & .82 & $90.7 \%$ & $3.1 \%$ & $6.3 \%$ \\
\hline $\begin{array}{l}\text { Brainstorming and finding } \\
\text { relevant information helped me } \\
\text { resolve content related } \\
\text { questions. }\end{array}$ & 4.19 & .93 & $78.2 \%$ & $15.6 \%$ & $6.3 \%$ \\
\hline $\begin{array}{l}\text { Online discussions were valuable } \\
\text { in helping me appreciate different } \\
\text { perspectives. }\end{array}$ & 4.09 & 1.09 & $75 \%$ & $15.6 \%$ & $9.4 \%$ \\
\hline $\begin{array}{l}\text { Combining new information helped } \\
\text { me answer questions raised in course } \\
\text { activities. }\end{array}$ & 4.13 & 1.01 & $84.4 \%$ & $6.3 \%$ & $9.4 \%$ \\
\hline $\begin{array}{l}\text { Learning activities helped me } \\
\text { construct explanations/solutions. }\end{array}$ & 4.16 & .99 & $81.3 \%$ & $12.5 \%$ & $6.3 \%$ \\
\hline
\end{tabular}




\begin{tabular}{lccccc}
\hline & Mean & SD & $\begin{array}{c}\text { \% } \\
\text { Agree }\end{array}$ & $\begin{array}{c}\text { \% } \\
\text { Neutral }\end{array}$ & $\begin{array}{c}\% \\
\text { Disagree }\end{array}$ \\
\hline $\begin{array}{l}\text { Reflections on course content } \\
\text { and discussions helped me }\end{array}$ & 3.91 & 1.17 & $68.7 \%$ & $15.6 \%$ & $15.6 \%$ \\
$\begin{array}{l}\text { understand fundamental } \\
\text { concepts in this class. }\end{array}$ & & & & & \\
$\begin{array}{l}\text { I can describe ways to test and } \\
\text { apply the knowledge created in this } \\
\text { course. }\end{array}$ & 3.94 & 1.13 & $78.2 \%$ & $9.4 \%$ & $12.5 \%$ \\
$\begin{array}{l}\text { I have developed solutions to course } \\
\text { problems that can be applied in } \\
\text { practice. }\end{array}$ & 4.00 & 1.14 & $81.3 \%$ & $6.3 \%$ & $12.5 \%$ \\
$\begin{array}{l}\text { I can apply the knowledge created } \\
\text { in this course to my work or other } \\
\text { non-class related activities. }\end{array}$ & 4.13 & 1.19 & $81.3 \%$ & $6.3 \%$ & $12.5 \%$ \\
\hline
\end{tabular}

Note. $\mathrm{n}=32 ; 5=$ strongly agree

Table 4 presents the survey results for social presence where students' ratings underscored a perception of open communication, including an easily discernible comfort level with: (a) "conversing through the online medium" $(M=4.53, S D=.76)$; "participating in course discussions" $(M=4.53, S D=.62)$; and (c) "interacting with other course participants" $(M=4.56$, $S D=.56)$. Students also felt they could "disagree with other course participants" $(M=4.50, S D=$ $.57)$ and that their "point of view was acknowledged" $(M=4.28, S D=.85)$. However, students did not unanimously perceive online or web-based communication as "an excellent medium for social interaction." While $65.6 \%$ of the ratings indicated agreement, $25 \%$ were neutral, and $9.4 \%$ disagreed.

\section{Table 4}

Social Presence (CoI): Means, Standard Deviations, and Percentages

\begin{tabular}{lccccc}
\hline & Mean & SD & $\begin{array}{c}\% \\
\text { Agree }\end{array}$ & $\begin{array}{c}\% \\
\text { Neutral }\end{array}$ & $\begin{array}{c}\text { \% } \\
\text { Disagree }\end{array}$ \\
\hline SOCIAL PRESENCE & 4.24 & .30 & & & \\
$\begin{array}{l}\text { Getting to know other course } \\
\text { participants gave me a sense of } \\
\text { belonging in the course. }\end{array}$ & 4.00 & .98 & $68.8 \%$ & $28.1 \%$ & $3.1 \%$ \\
$\begin{array}{l}\text { I was able to form distinct } \\
\text { impressions of some course } \\
\text { participants. }\end{array}$ & 3.91 & 1.06 & $75.1 \%$ & $12.5 \%$ & $12.5 \%$ \\
$\begin{array}{l}\text { Online or web-based } \\
\text { communication is an excellent } \\
\text { medium for social interaction. }\end{array}$ & 3.84 & .95 & $65.6 \%$ & $25 \%$ & $9.4 \%$ \\
$\begin{array}{l}\text { I felt comfortable conversing } \\
\text { through the online medium. }\end{array}$ & 4.53 & .76 & $90.6 \%$ & $6.3 \%$ & $3.1 \%$ \\
\hline
\end{tabular}




\begin{tabular}{|c|c|c|c|c|c|}
\hline & Mean & SD & $\begin{array}{c}\% \\
\text { Agree }\end{array}$ & $\begin{array}{c}\% \% \\
\text { Neutral }\end{array}$ & $\begin{array}{c}\% \\
\text { Disagree }\end{array}$ \\
\hline $\begin{array}{l}\text { I felt comfortable participating } \\
\text { in the course discussions. }\end{array}$ & 4.53 & .62 & $93.8 \%$ & $6.3 \%$ & $0.0 \%$ \\
\hline $\begin{array}{l}\text { I felt comfortable interacting with } \\
\text { other course participants. }\end{array}$ & 4.56 & .56 & $96.9 \%$ & $3.1 \%$ & $0.0 \%$ \\
\hline $\begin{array}{l}\text { I felt comfortable disagreeing with } \\
\text { other course participants while } \\
\text { still maintaining a sense of trust. }\end{array}$ & 4.50 & .57 & $96.9 \%$ & $3.1 \%$ & $0.0 \%$ \\
\hline $\begin{array}{l}\text { I felt that my point of view was } \\
\text { acknowledged by other course } \\
\text { participants. }\end{array}$ & 4.28 & .85 & $87.5 \%$ & $6.3 \%$ & $6.3 \%$ \\
\hline $\begin{array}{l}\text { Online discussions help me to } \\
\text { develop a sense of collaboration. }\end{array}$ & 4.00 & 1.16 & $71.9 \%$ & $18.8 \%$ & $9.4 \%$ \\
\hline
\end{tabular}

Note. $\mathrm{n}=32 ; 5=$ strongly agree

\section{RQ 2: How Can We Characterize Learner Presence?}

The interviews addressed RQ 2. The learner thoughts and actions described in the interviews were categorized thematically by the researchers as Learner Intentions, Learner Metacognition, and Peer Monitoring. Table 5 presents explanatory definitions of these three concepts and defines the purposeful learner actions referred to by over half of the interview participants. These definitions encapsulate students' responses across interviews.

We represented specific learner actions described in the interviews in a concept map comprising three main concepts (see Figure 2). The Learner Intentions concept represented a stance or orientation in which the MBA students began their online course. Learners consistently looked for instructor expectations and sought both familiarity (organization and content) and professional applicability. The Learner Metacognition and Peer Monitoring concepts continued to reflect these learner intentions but in a deeper way as they participated in a course. Learner metacognition involved self-reflection in relation to course activity demands. Specifically, learners made explicit connections between the content/activity and their interests/goals, refined their professional perspectives, sought and used feedback, and looked for additional practice opportunities. The Peer Monitoring concept described by MBA learners seemed to go beyond the CoI notion of social presence as it involved a professionally relevant evaluative aspect. MBA learners sought out contributing peers in the online environment and in doing so, evaluated their peers' effort in course assignments and discussions according to their potential to advance their own learning goals. 
Table 5

Learner Presence Concepts

\section{Learner Intentions}

Look for instructor expectations

Seek familiarity

Seek professional relevance/applicability
Attempting to determine the instructor/course expectations either weekly or overall. For example, noting the type and weighting of assignments and determining what resources would be needed to complete them; looking for instructor's availability and instructor's general expectations. Explicitly looking for familiarity in the course organization as well as specific business concepts. Referred to familiar online course layout that they sought or preferred for ease of access. Similarly, sought and noted specific business concepts from prior coursework or professional experience.

Making connections to workplace experiences and challenges; Looking for how the course may help solve a persistent work-related problem or may contribute to professional self-development. For example, referred to analyzing cases for personal meaning, relating the issues and dynamics in their own professional experiences in areas such as leadership, finance, and economics.

\section{Learner Metacognition}

Look for practice opportunities

Looking for tutorials or ways to test understanding. For example, engaging in self-directed, extra-curricular advance preparation for participating in a complex business simulation.

Gaining new insights into own experiences in the business world. For example, describing new ways of thinking about their managerial practice, such as reflecting on the implications of making decisions based on imperfect information.

In selecting topics for papers or discussion posts, learners were able to discern the topics in which they had the greatest interest. For example, describing a high value for the opportunity to write or present on topics in which they had a particular professional interest.

Looking for and/or applying input from the instructor on discussion posts or other assignments; derived motivation from feedback. For example,

Seek/use feedback communicating a strong desire for multiple forms of instructor feedback that provide correct vs. incorrect, follow-up questions to prompt deeper thinking, or identification of major takeaways.

\section{Peer Monitoring}

Assessing peers in the course for what they may offer on the topic and how they may help extend learner's growth. For example, reviewing the

Seek contributing peers course introductions for information about class colleagues' professional and demographic backgrounds (i.e., experience, age); identifying peers who contribute effectively.

Evaluating peer commitment to discussions and assignments. For example, made attributions about class colleagues' posted work and Evaluate peer effort described a preference to correspond with class colleagues whose work they viewed as consistently high-level. Referred to peer feedback as a valuable driver of learning new perspectives. 


\section{Figure 2}

Learner Presence Concepts in MBA Learning Environment.

What is the nature of learner presence in an accelerated MBA Community of Inquiry?

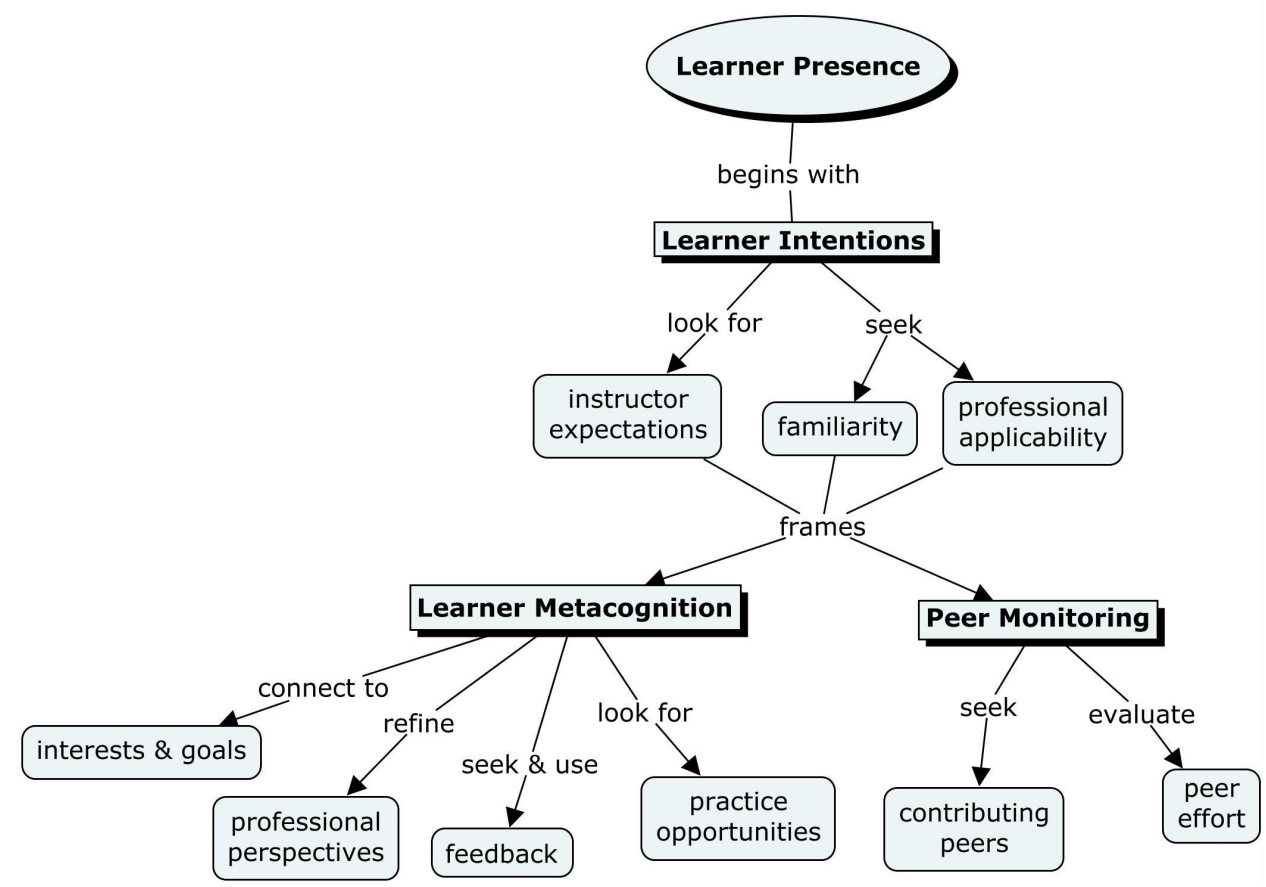

\section{Discussion}

The survey and interview results provided an affirmative answer to the question of whether students in an accelerated MBA Program experience their courses as a community of inquiry. CoI survey ratings showed that course organization (teaching presence) and exploration (cognitive presence) figured prominently in students' experience of CoI. Interview responses indicated that MBA students particularly valued the predictable organization provided by the program course design template, and they valued choice in the exploration of course content. Social presence, as expressed through "comfort" in communication, also was strongly rated, a meaningful accomplishment given that students may not universally perceive web-based communication as an optimal social interaction approach. Students' interview responses described vigilance in monitoring their peers' thoughts and actions in the course. Indeed, the interview responses were particularly interesting for their context-specific illustration of learner presence. MBA learners arrived in their courses with specific learner intentions that framed their metacognitive posture and impacted the way they approached peer learning. In this regard, learner presence in this MBA learning environment entailed aspects of self-regulation (Zimmerman, 2008). Learners sought to connect coursework to professional interests and goals, monitored and refined their professional perspectives through feedback-seeking and practice, and strategically evaluated their peers to maximize learning. 
In the present study, we adopted a different approach than prior research involving largesample collection of self-ratings across educational contexts (e.g., Shea \& Bidjerano, 2010) or analysis of student discourse within collaborative activities (Shea et al., 2012). Characteristics of learner presence were derived from learners' own descriptions of their thoughts and actions in particular course environments. While the findings shared commonalities with the large scale research in terms of critical self-regulatory skills, they also offered a more nuanced view of these skills to which the contextual factors of course acceleration, a program-wide course template, and a professionally experienced student population seemed to be inextricably tied. Closer examination demonstrated why it is beneficial for CoI research to acknowledge program contexts and to more deeply understand the nature of learners' presence in these contexts.

Importantly, it appeared that course acceleration did not preclude the development of CoI, a finding that is consistent with prior research (e.g., Akyol et al., 2011). In fact, course acceleration may propel the highly focused learner stance (Learner Intentions) described in the interviews. On entering a short course, MBA learners swiftly sought instructor expectations, familiarity of content or course layout, and professional applicability. There was clear intentionality with respect to situating oneself in the course and assessing learning potential. As one learner observed, "With each course, I read through the objectives to understand the goals and what I want to achieve."

The program-wide implementation of a standard online course template was another interesting contextual feature which heightened teaching presence and acted as a support mechanism where learner stance was concerned. The consistent course layout offered cross-course familiarity (a component of Learner Intentions) via specially designed pages for learning goals, activity instructions, due dates, and grading turnaround times. This was a high-impact design approach for an accelerated MBA Program, and it produced high ratings for course organization.

Finally, the MBA learners in this study rated the quality of social presence as high, yet their interview responses suggested they do not automatically value it. Learner stance once again came into play as learners strategically sought class colleagues whom they believed would contribute to their focused learning goals. Moreover, they evaluated peers with respect to perceived effort in online class discussions and on assignments, deciding carefully where they would read and offer responses of their own. One learner overtly described a search for "...posts that are worthy of inquiry and response." In this area of peer monitoring, learners' thoughts and actions seemed to go beyond what is measured by the CoI survey-i.e., these MBA learners framed social interaction in the course as less about affirmation and comfort and more about assessing peers for what they could offer and how they could contribute to a learner's professional growth.

\section{What Features of the CoI Framework Seem to Support Learner Presence?}

The surfacing of the three contextually specific qualities of learner presence-Learner Intentions, Learner Metacognition, Peer Monitoring — offered essential insight into how the MBA students regulated their learning and led to the important follow-up question, What features of the CoI framework seemed to support this learner presence? While directionality between learner presence and the CoI presences was not specifically measured in this research, interview responses suggested that learner presence was connected with each of the three CoI presences and moreover, that each of the three presences played a role in supporting it. While connected with the CoI presences, learner presence was unique with respect to orientation and encapsulated a perspective on directing one's own learning (which is not evident in the CoI framework or CoI Survey). 
Not surprisingly, teaching presence figured prominently in students' remarks, and students referenced numerous course-related features that seemed associated with the CoI concept of teaching presence. These included a coherent course design and a predictable course structure as well as messaging (via the course website, syllabus, and objectives) about how a given course would support them professionally and career-wise. As noted earlier, the course template played an important role in this respect and served as a very good example of how teaching presence (through course design) can support learner presence.

Students also referred to and valued feedback that provided clarity and validation (such as feedback on assignments) as well as when instructors deepened student reflection and thinking through probing, scaffolding, and contextualizing. This notion of teaching presence extended beyond timeliness of feedback, which was highly rated by MBA students on the CoI survey but which did not fully capture the nature of the feedback that MBA students sought as they managed their learning trajectory in a course. MBA students recognized the online discussion forum as the main interaction space in any given online course, and they saw the important role that the instructor can play in facilitating deep, authentic discourse in this medium. While the instructor role in course discussions has been debated in the literature (e.g., Preisman, 2014), the MBA learners in our sample overtly referenced the value of interacting with faculty in online course discussion: "I would have loved for the instructor to engage in the discussion threads with students beyond just commenting on them - maybe asking follow-up questions to provoke ongoing conversation or connecting students to other students who had made related or conflicting arguments." The students' CoI survey ratings confirmed that teaching presence could be boosted in this environment through increased faculty participation in online course discussions.

Students referred to and valued relatable content and assignments (including online discussions) particularly those that allowed choice in researching subjects of professional interest. These features aligned well with the concept of cognitive presence and suggested the importance of "trigger" assignments (stage 1 in the practical inquiry cycle) that are meaningful to MBA learners in order to engage their metacognition. The MBA students were very self-aware with respect to their interests and goals. They valued learning activities that allowed for reflection on their managerial practice as well as issues emerging in their workplace. The students themselves provided guidance in this area: "I found the most benefit from the reflections exercises. It allowed me to think about what I learned and how it is relevant to my life. I am completely rethinking my career as a result."

Finally, the MBA students referred to features of the course social environment that influenced their learning. Specifically, they mentioned the importance of meaningful interactions with peers and the equitable distribution of responsibilities among peers (e.g., role assignment in teamwork projects). This crucially important area raised the specter of preparing students to act as continuously contributing MBA-CoI members who shared a responsibility to co-create meaningful interactions and discourse in the CoI. Learner intentions played a critical role because while MBA students may appreciate online camaraderie, they were much more geared toward evaluating social interaction for its potential contribution to learning. CoI survey ratings suggested social presence was high, but what MBA learners additionally needed was a strong learner presence among their peers. The notion that an online community of students should act as an integral team that codevelops high-level discourse in the service of "new learning" implies a needed shift in the MBA learning culture. Specifically, MBA course designs might create greater demand for teamwork and help students learn how to use teaming to learn-a skill set surely needed in the workplace. Various 
teamwork tools and techniques could be systematically incorporated in online MBA courses just as they are implemented in business.

\section{Focusing on Learner Presence}

Taken together, the CoI survey and interview results identified practical considerations in preparing courses (e.g., activities, interaction space), learners, and instructors to co-construct an MBA CoI. Importantly, they also contributed to our understanding of learner presence and how it may interact with the CoI presences. Perhaps the most compelling element of the current research was the affordances it provided to examine CoI-related dynamics in a specific learning context. The integration of quantitative (CoI survey) and qualitative (interviews) methods was especially useful as the CoI survey generally pointed out strengths and weaknesses in the CoI presences while the interview data surfaced insights into how the three presences could be heightened to support and enhance MBA learner presence.

We summarized the CoI features that seemed to matter most to our MBA learners through a graphic representation (see Figure 3). This representation offers a subtle reinterpretation of the original CoI framework, or perhaps a more specific interpretation of educational experience. In replacing educational experience (or learning experience) with learner presence at the center of the overlapping CoI presences, the language explicitly communicates a learner-centered focus within a community of inquiry. Learner presence as the intersection of the three CoI presences privileges learner skill/expertise when developing or teaching a course. It is meant to foreground the learner as an active agent in the evolution of the course learning experience.

\section{Figure 3}

MBA Learner Presence Within the CoI Framework.

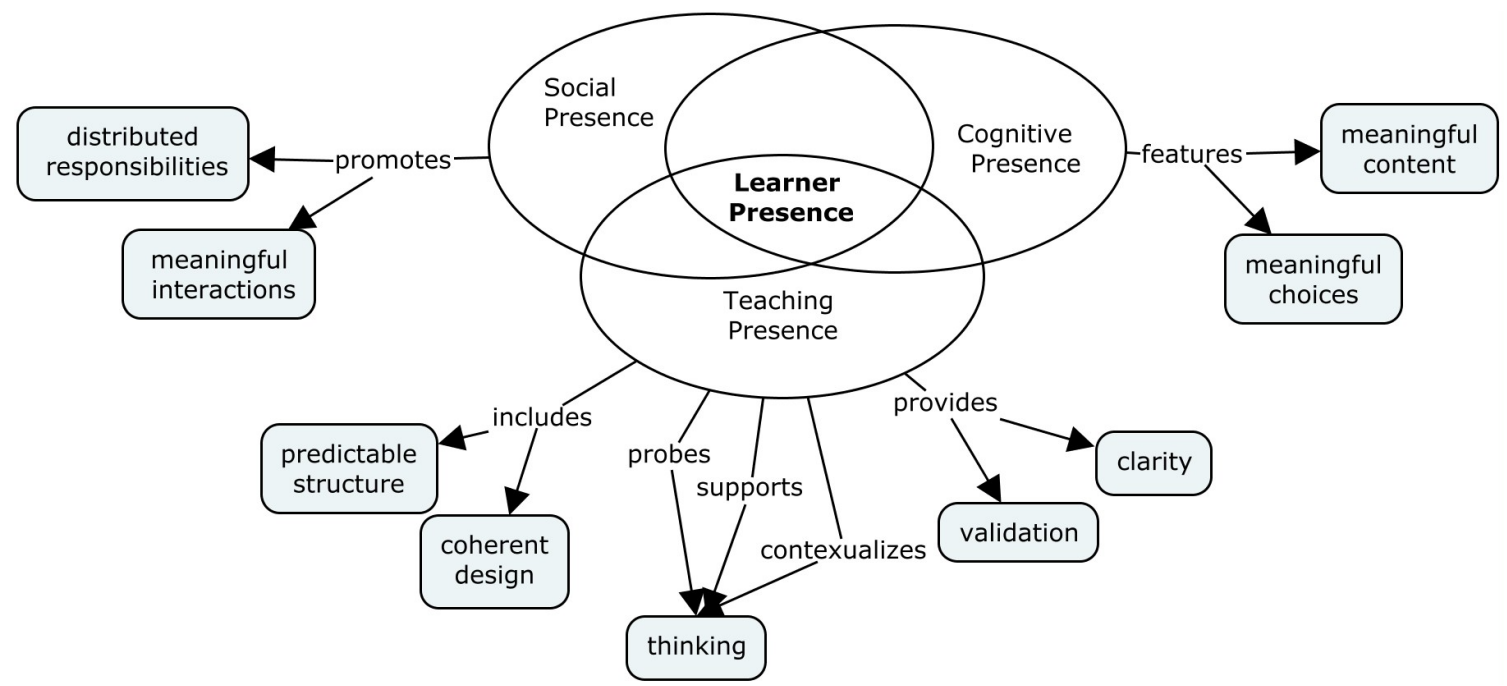


One might consider the presences in this modified $\mathrm{CoI}$ as a set of intersecting lenses through which the learning process can be viewed. Critically, learners bring their own lens through which they view and interpret the other CoI presences and what they appreciate or need them to be. Hence, faculty and instructional designers need to start with the learner lens (i.e., learner presence) and "dial" or adjust the other lenses to accord with expected learners' intentions, metacognitive skill, and potential for peer collaboration. Some of the CoI qualities may be "constants" that are set at the start of a course and which create thresholds for teaching presence, cognitive presence, and social presence-based on known learner features. Other CoI qualities may be "variables" requiring in-the-moment monitoring and adjustment throughout the course. For example, weekly class discussions may be a threshold "social presence" requirement (i.e., a constant) for an online class in leadership, but this presence could be "dialed up" to support MBA learner presence by including real-time discussion (e.g., web conferencing) or asynchronous voice/video discussion (e.g., VoiceThread) as these contemporary interaction methods might afford MBA learners an opportunity to more fully observe and assess their peers' contributions to the learning environment (an element of learner presence in this MBA learning environment). A more fluid or variable element in this example would be continually (re)focusing the teaching presence lens to provide contextualized, probing guidance that sparks deeper discussion and helps students develop and refine their own thinking and responses. Overall, the general thesis is that knowing the learners, their intentions, metacognitive skill, and peer relationships, allows for the strategic design of constants and thoughtful monitoring of variables within the three CoI presences.

This shift in the framework toward an explicit and expanded role for learner presence complements and builds upon previous research. Our notion bears a relationship to Lam's (2015) description of autonomy presence, wherein students direct their learning behaviors as a function of intrinsic motivation. It also bears a relationship to the large-sample research conducted by Shea \& Bidjerano $(2010,2012)$ that demonstrated how students' self-regulatory behaviors "dynamically" interact with teaching presence and social presence and also may play a moderating function with respect to the $\mathrm{CoI}$ presences. A distinguishing element in the current research, however, is the extensive contextualization of learner presence to reflect how the MBA students discussed their agency in relation to the three CoI presences. In addition, the current research did not search for causality or directionality among the CoI presences and learner presence, but rather, assumed a complex, dynamic interplay and mutuality among the learner presence and the three CoI presences.

\section{Learner Presence Across Contexts: Potential Parallel Pathways Forward}

This research study's deep examination of learner presence within one specific learning context offered a unique approach to surfacing the complex interplay between the features of CoI and skilled MBA learners' perspective on what the learning experience actually was like for them and how it ideally should unfold. Affording a representative group of MBA learners an opportunity to describe and reflect on their course experiences - and linking those descriptions and reflections to CoI-provided essential program-level insights. The findings in this MBA learning context where learner presence involved professional goals and self-regulated learning through practice, feedback, and reflection, suggest that beneficial faculty development might entail how to customize assignments, provide in-depth feedback, and effectively guide online discussions.

Arguably, it is the value of the approach itself that emerges as the principal and most generalizable outcome of the study. The use of the CoI Survey augmented through stimulated recall interviews added depth and nuance to our understanding of the learner presence construct to 
include learner's intentions, metacognitive strategies, and peer monitoring strategies. This pathway surfaced a learner-directed, context-specific, and CoI-connected definition of learner presence. Parallel pathways (i.e., investigations in additional learning contexts) that examine the nature of learner presence through a similar approach can further deepen our understanding of this emergent construct. The implication is that learner presence may not be a static collection of immutable qualities and, through the process applied in this study, might more likely be defined distinctively in different contexts based on program, course, or learner history. At the level of the individual course or program, one can envision cycles of action research that commence when emergent qualities of learner presence are derived from learners' reflections and used to inform course design and improve pedagogical practice.

Faculty researchers applying the process used in this study might develop a compendium of survey questions to measure learner presence in a given course or program learning context. Such a compendium could be offered as an option to add to the CoI Survey. The content analysis and mapping procedure reported in the present study provided a strong representation of the interchange among the CoI presences and learner presence in one academic program. However, the development of follow-up survey questions would allow for ongoing tracking of contextspecific learner presence and would shed additional light on the relationship between learner presence and the CoI presences.

\section{Limitations and Future Research}

The small, select sample in this study allowed for an in-depth, context-specific examination of $\mathrm{CoI}$ and learner presence. However, the sample size and single context may also be viewed as limitations. Future research on CoI might further elaborate learner presence in additional, specific learning environments. For example, how might learner presence be defined in other academic disciplines? What similarities and differences emerge across disparate professional programs (e.g., engineering or teaching)? Do undergraduate students exhibit the same degree of intentionality and metacognition as graduate students? Are there additional demographic stratifications that would inform our understanding of learner presence? Clearly, findings from such contextualized CoI research can better inform continuous course improvement efforts as well as the design of CoIbased faculty development programs. Indeed, faculty-wide comprehension and acknowledgement of the nature of learner presence and its nuances within particular learning communities represents an opportunity for cultivating effective learning experiences and advancing CoI.

\section{Author Note}

This research was supported by a seed grant from the National Louis University Seed Grant Program.

Correspondence concerning this article should be addressed to Catherine A. Honig, Ph.D., College of Professional Studies and Advancement, National Louis University, 122 S. Michigan Ave., Chicago, IL, 60603. Email: chonig@nl.edu 


\section{References}

Akyol, Z., Vaughan, N., \& Garrison, D. R. (2011). The impact of course duration on the development of a community of inquiry. Interactive Learning Environments, 19(3), 231246. https://doi.org/10.1080/10494820902809147

Allen, I. E., \& Seaman, J. (2016). Online report card: Tracking online education in the United States. Babson Survey Research Group and Quahog Research Group. http://www.onlinelearningsurvey.com/reports/onlinereportcard.pdf

Allen, I. E., \& Seaman, J. (2017). Digital learning compass: Distance education enrollment report 2017. Babson Survey Research Group, e-Literate, and WCET. https://onlinelearningsurvey.com/reports/digtiallearningcompassenrollment2017.pdf

Anderson, T. (2018, February 1). How communities of inquiry drive teaching and learning in the digital age. Contact North | Contact Nord. https://teachonline.ca/toolstrends/insights-online-learning/2018-02-27/how-communities-inquiry-drive-teachingand-learning-digital-age

Anderson, T., Rourke, L., Garrison, R., \& Archer, W. (2001). Assessing teaching presence in a computer conferencing context. Online Learning, 5(2), 1-17. https://doi.org/10.24059/olj.v5i2.1875

Arbaugh, J. B. (2007). An empirical verification of the community of inquiry framework. Online Learning, 11(1), 73-85. https://doi.org/10.24059/olj.v11i1.1738

Arbaugh, J. B. (2008). Does the community of inquiry framework predict outcomes in online MBA courses? The International Review of Research in Open and Distributed Learning, 9(2). https://doi.org/10.19173/irrodl.v9i2.490

Arbaugh, J. B., Cleveland-Innes, M., Diaz, S. R., Garrison, D. R., Ice, P., Richardson, J. C., \& Swan, K. P. (2008). Developing a community of inquiry instrument: Testing a measure of the community of inquiry framework using a multi-institutional sample. The Internet and Higher Education, 11(3-4), 133-136. https://doi.org/10.1016/j.iheduc.2008.06.003

Belsky, L. (2019, October 4). Where online learning goes next. Harvard Business Review Digital Articles. https://hbr.org/2019/10/where-online-learning-goes-next

Bettinger, E., \& Loeb, S. (2017, June 9). Promises and pitfalls of online education. Brookings Institution. https://www.brookings.edu/research/promises-and-pitfalls-of-onlineeducation/

Boston, W., Diaz, S. R., Gibson, A. M., Ice, P., Richardson, J., \& Swan, K. (2009). An exploration of the relationship between indicators of the community of inquiry framework and retention in online programs. Online Learning, 13(3). https://doi.org/10.24059/olj.v13i3.1657 
Diaz, S. R., Swan, K., Ice, P., \& Kupczynski, L. (2010). Student ratings of the importance of survey items, multiplicative factor analysis and the validity of the community of inquiry survey. The Internet and Higher Education, 13(1-2), 22-30. https://doi.org/10.1016/j.iheduc.2009.11.004

Garrison, D. R. (2009). Communities of inquiry in online learning. In P. Rogers, G. Berg, J. Boettcher, C. Howard, L. Justice, \& K. Schenk (Eds.), Encyclopedia of distance learning, Second edition (pp. 352-355). Hershey, PA: IGI Global. https://doi.org/10.4018/978-160566-198-8.ch052

Garrison, D. R. (2017, October 24). Other presences? The Community of Inquiry. http://www.thecommunityofinquiry.org/editorial7

Garrison, D. R., \& Akyol, Z. (2013). Toward the development of a metacognition construct for communities of inquiry. The Internet and Higher Education, 17, 84-89. https://doi.org/10.1016/j.iheduc.2012.11.005

Garrison, D. R., Anderson, T., \& Archer, W. (2000). Critical inquiry in a text-based environment: Computer conferencing in higher education. The Internet and Higher Education, 2(2-3), 87-105. https://doi.org/10.1016/S1096-7516(00)00016-6

Garrison, D. R., Anderson, T., \& Archer, W. (2001). Critical thinking, cognitive presence, and computer conferencing in distance education. American Journal of Distance Education, 15(1), 7-23. https://doi.org/10.1080/08923640109527071

Garrison, D. R., Anderson, T., \& Archer, W. (2010). The first decade of the community of inquiry framework: A retrospective. The Internet and Higher Education, 13(1-2), 5-9. https://doi.org/10.1016/j.iheduc.2009.10.003

Garrison, D. R., \& Arbaugh, J. B. (2007). Researching the community of inquiry framework: Review, issues, and future directions. The Internet and Higher Education, 10(3), 157172. https://doi.org/10.1016/j.iheduc.2007.04.001

Garrison, D. R., \& Cleveland-Innes, M. (2005). Facilitating cognitive presence in online learning: Interaction is not enough. American Journal of Distance Education, 19(3), 133148. https://doi.org/10.1207/s15389286ajde1903_2

Garrison, D. R., Cleveland-Innes, M., \& Fung, T. (2010). Exploring causal relationships among teaching, cognitive and social presence: Student perceptions of the community of inquiry framework. The Internet and Higher Education, 13(1-2), 31-36. https://doi.org/10.1016/j.iheduc.2009.10.002

Hayes, S., Uzuner Smith, S., \& Shea, P. (2015). Expanding learning presence to account for the direction of regulative intent: Self-, co- and shared regulation in online learning. Online Learning, 19(3). http://dx.doi.org/10.24059/olj.v19i3.530 
Lam, J. (2015). Autonomy presence in the extended community of inquiry. International Journal of Continuing Education and Lifelong Learning, 8(1), 39-61.

Lambert, J. L., \& Fisher, J. L. (2013). Community of inquiry framework: Establishing community in an online course. Journal of Interactive Online Learning, 12(1), 1-16.

Nguyen, T. (2015). The effectiveness of online learning: Beyond no significant differences and future horizons. Journal of Online Teaching \& Learning, 11(2), 309-319.

Picciano, A. G. (2017). Theories and frameworks for online education: Seeking an integrated model. Online Learning, 21(3), 166-190. http://dx.doi.org/10.24059/olj.v21i3.1225

Pool, J., Reitsma, G., \& van den Berg, D. (2017). Revised community of inquiry: Examining learning presence in a blended mode of delivery. Online Learning, 21(3), 153-165. https://doi.org/10.24059/olj.v21i3.866

Preisman, K. A. (2014). Teaching presence in online education: From the instructor's point of view. Online Learning, 18(3). https://doi.org/10.24059/olj.v18i3.446

Seaman, J. E., Allen, I. E., \& Seaman, J. (2018). Grade increase: Tracking distance education in the United States. Babson Survey Research Group. http://onlinelearningsurvey.com/reports/gradeincrease.pdf

Shea, P., \& Bidjerano, T. (2010). Learning presence: Towards a theory of self-efficacy, selfregulation, and the development of communities of inquiry in online and blended learning environments. Computers \& Education, 55(4), 1721-1731. https://doi.org/10.1016/j.compedu.2010.07.017

Shea, P., \& Bidjerano, T. (2012). Learning presence as a moderator in the community of inquiry model. Computers \& Education, 59(2), 316-326. https://doi.org/10.1016/j.compedu.2012.01.011

Shea, P., Hayes, S., Uzuner Smith, S., Vickers, J., Bidjerano, T., Gozza-Cohen, M., Jian, S., Pickett, A., Wilde, J., \& Tseng, C. (2013). Online learner self-regulation: Learning presence viewed through quantitative content- and social network analysis. The International Review of Research in Open and Distributed Learning, 14(3), 427-461. https://doi.org/10.19173/irrodl.v14i3.1466

Shea, P., Hayes, S., Uzuner Smith, S., Vickers, J., Bidjerano, T., Pickett, A., Gozza-Cohen, M., Wilde, J., \& Jian, S. (2012). Learning presence: Additional research on a new conceptual element within the community of inquiry $(\mathrm{CoI})$ framework. The Internet and Higher Education, 15(2), 89-95. https://doi.org/10.1016/j.iheduc.2011.08.002 
Shea, P., Hayes, S., \& Vickers, J. (2010). Online instructional effort measured through the lens of teaching presence in the community of inquiry framework: A re-examination of measures and approach. The International Review of Research in Open and Distributed Learning, 11(3), 127-154. https://doi.org/10.19173/irrodl.v11i3.915

Swan, K. P., Richardson, J. C., Ice, P., Garrison, D. R., Cleveland-Innes, M., \& Arbaugh, J. B. (2008). Validating a measurement tool of presence in online communities of inquiry. $E$ Mentor, 2 (24).

http://www.e-mentor.edu.pl/_streszczenia_eng/swan_n24.html

Swan, K., \& Shih, L. F. (2005). On the nature and development of social presence in online course discussions. Online Learning, 9(3), 115-136.

https://doi.org/10.24059/olj.v9i3.1788

Zimmerman, B. J. (2008). Investigating self-regulation and motivation: Historical background, methodological developments, and future prospects. American Educational Research Journal, 45(1), 166-183. https://doi.org/10.3102/0002831207312909 
Appendix A

MBA Interview Protocol

We want you to take us through some of your experiences in the course by asking you to think aloud about these six course components. We are going to refer to one of your MBA courses to get your perspective on how you experienced 3 major course elements: the overall content organization, the discussion forums, and the main course assignments. Then we'll zoom in on each of those to hear your thoughts about one particular module, discussion, or assignment that stood out to you.

- To get an overview of the course organization - We'll look at the table of contents (and perhaps the course schedule - as needed).

General: What were your thoughts as you initially reviewed the course content or course organization? What was your overall first impression?

- What were your preparatory actions? How did you get underway?

- Anything else on your initial impressions or actions?

Particular: As you look at the table of contents, was there a particularly compelling module for you?

- Tell us about it? Why was it compelling?

\section{- Let's turn to the discussion forums}

General: How did you generally experience the discussion forums in this course?

- You might think about the quality of the topics, the questions, the posts, the pace of interaction, and how they enabled you to learn about the concepts.

Particular: Reviewing the discussion forums, was there a particularly compelling discussion? Tell us about it? Why was it compelling? Did one stand out to you?

\section{- Let's think about the course assignments}

General: How did you experience the assignments in this course -- overall?

- Was there a particularly compelling assignment? Which assignment stood out to you in this course? Why?

- What did it require you to do? How did it engage your thinking on the topic? Did the assignment make you aware of your own learning or your own topic knowledge?

Is there anything else about these course components that you would like to tell us? 